\title{
Intersectionality as a Lens to Promote Equity and Inclusivity within SIGCHI
}

DOI:

$10.1145 / 3170427.3186324$

Document Version

Accepted author manuscript

Link to publication record in Manchester Research Explorer

\section{Citation for published version (APA):}

Wisniewski, P., Kumar, N., Bassem, C., Clinch, S., Dray, S., Fitzpatrick, G., Lampe, C., Muller, M., \& Peters, A. (2018). Intersectionality as a Lens to Promote Equity and Inclusivity within SIGCHI. 2018 ACM CHI Conference on Human Factors in Computing Systems, Montréal, Canada. https://doi.org/10.1145/3170427.3186324

\section{Citing this paper}

Please note that where the full-text provided on Manchester Research Explorer is the Author Accepted Manuscript or Proof version this may differ from the final Published version. If citing, it is advised that you check and use the publisher's definitive version.

\section{General rights}

Copyright and moral rights for the publications made accessible in the Research Explorer are retained by the authors and/or other copyright owners and it is a condition of accessing publications that users recognise and abide by the legal requirements associated with these rights.

\section{Takedown policy}

If you believe that this document breaches copyright please refer to the University of Manchester's Takedown Procedures [http://man.ac.uk/04Y6Bo] or contact uml.scholarlycommunications@manchester.ac.uk providing relevant details, so we can investigate your claim.

\section{OPEN ACCESS}




\section{Intersectionality as a Lens to Promote Equity and Inclusivity within SIGCHI}

Pamela Wisniewski

University of Central Florida

(USA)

pamwis@ucf.edu

\section{Neha Kumar}

Georgia Institute of Technology

(USA)

neha.kumar@gatech.edu

Christine Bassem

Wellesley College (USA)

cbassem@wellesley.edu

\section{Sarah Clinch}

University of Manchester (UK)

sarah.clinch@manchester.ac.uk

\section{Susan Dray}

Dray \& Associates, Inc. (USA)

Susan.dray@dray.com

\section{Geraldine Fitzpatrick}

TU Wien (Austria)

geraldine.fitzpatrick@tuwien.ac.at

\section{Cliff Lampe}

University of Michigan (USA)

cacl@umich.edu

\section{Michael Muller}

IBM Research AI (USA)

michael_muller@us.ibm.com

\section{Anicia Peters}

Namibia University of Science \&

Tech (Namibia)

anicia.peters@gmail.com

Paste the appropriate copyright/license statement here. ACM now supports three different publication options:

- ACM copyright: ACM holds the copyright on the work. This is the historical approach.

- License: The author(s) retain copyright, but ACM receives an exclusive publication license.

- Open Access: The author(s) wish to pay for the work to be open access. The additional fee must be paid to ACM.

This text field is large enough to hold the appropriate release statement assuming it is single-spaced in Verdana 7 point font. Please do not change the size of this text box.

Each submission will be assigned a unique DOI string to be included here.

\begin{abstract}
The ACM SIGCHI community has been at the forefront of addressing issues of equity and inclusivity in the design and use of technology, accounting for various aspects of users' identities such as gender, ethnicity, and sexuality. With this panel, we wish to explore how we, as SIGCHI, might better target similar goals of equity and inclusivity-across intersections-within our own community. We wish to create a forum for recognizing best practices regarding equity and inclusivity in participants' local and global contexts that we might feasibly integrate across SIGCHI. By equally prioritizing the voices of those in the audience and on the panel, we intend to foster a lively and constructive discussion that will help us chart a way forward. The takeaways from this panel will be articulated into an article for the Interactions magazine, targeting the larger human-computer interaction (HCI) community.
\end{abstract}

\section{Author Keywords}

Intersectionality; Diversity; Equity; Inclusion; SIGCHI

\section{ACM Classification Keywords}

H.5.m. Information interfaces and presentation (e.g., HCI): Miscellaneous. 


\section{Introduction}

At CHI 2017, Schlesinger, Edwards, and Grinter made a call for an Intersectional $\mathrm{HCI}$, emphasizing the need for $\mathrm{HCI}$ research to recognize the intersections of diverse aspects of users' identities, including their race, gender, and class, but also other aspects such as nationality and/or sexuality [11]. They highlighted how research at $\mathrm{CHI}$ had thus far failed to engaged with intersectionality in a meaningful way. Since then, workshops at the CSCW and IDC conferences [4, 12] have also stressed the importance of thinking about intersections in $\mathrm{HCI}$ research, but again, focusing on the intersections where research subjects are located.

Our panel aims to raise intersectional sensitization with regards to the identities of members within SIGCHI reflecting on how we might co-create a more equitable and inclusive community. We will begin by recognizing efforts that SIGCHI has made over the years, in generally being ahead of the curve with its current constitution and efforts towards inclusive growth. We will then invite participation from our audience and panel regarding best practices in other local/global research communities that might strengthen our own, identifying concrete steps forward.

Our panel is one of many initiatives of the Fostering the Future of Computing working group-part of the ACM Future of Computing Academy (FCA). Pamela, Neha, Christine, and Sarah are members of the FCA, this working group, and SIGCHI. We aim to inform best practices for equity and inclusivity in the ACM.

1 The above questions are modeled after the "I like, I wish, What if" format that is part of the Stanford University d.school's

\section{Panel Overview}

Questions ${ }^{1}$ we plan to raise in our panel include:

1. What have we learned from the ways in which the SIGCHI community has successfully addressed matters of equity and inclusion that have yielded measurable, positive outcomes? Are there other research communities that have performed well in this regard?

2. Are there ways in which intersections that exist within the SIGCHI community have not been recognized adequately and/or appropriately?

3. How might we, as individuals and a community, work towards a more equitable and inclusive SIGCHI, particularly at recognized intersections?

We will ensure that these questions are addressed in a healthy, constructive dialog, by all voices, particularly those at the intersections we highlight next.

\section{Intersections to Consider}

Brah and Phoenix defined intersectionality as "the complex, irreducible, varied, and variable effects which ensue when multiple axes of differentiation-economic political cultural, psychic, subjective and experientialintersect in historically specific contexts" [2]. Originally introduced by Crenshaw as a frame for recognizing dimensions of the experiences and struggles of black women [3], intersectionality is frequently used to refer to "different kinds of difference" and for understanding the impact of such difference [10]. Below, we identify kinds of difference that continue to shape the SIGCHI community and may merit greater attention than they

method repository [13]. It allows for carefully constructed feedback to ensure that the conversations remain generative. 
have received. We then attend to how some of these might intersect to make a greater impact.

\section{Global Diversity}

In recent years, SIGCHI has made many efforts to increase its global reach. Most recent undertakings include the SIGCHI Across Borders Initiative being led by Susan and Cliff (panelists), HCI Across Borders symposia, and multiple Development Consortia organized through the years [7]. The institution of the Gary Marsden Development Fund has been an additional push towards inviting greater participation at a global level, for both less and more experienced $\mathrm{HCI}$ researchers. However, there is much progress to be made in this regard. How might SIGCHI work more extensively to support and foster regional expertise in $\mathrm{HCI}$ far from the U.S. and in emerging economies? This may also require being better prepared to deal with political complications such as travel bans and visa issues, the subject of much discussion last year [6].

Under-Representation of Race and Ethnicity From a race and ethnicity perspective, a mere glance would indicate that the SIGCHI community lacks equal representation. Often, this results in outsiders speaking in place of the members of that constituency, leading to problems of whose voice is heard [8]. Are there efforts ongoing within SIGCHI to recognize and/or improve these statistics? Are there other disciplines (that the audience is aware of) that might better address this gap? What might be challenges that our community must contend with when we do not recognize or do not address this concern?

\section{Gender Inequity}

Historically, SIGCHI has had a larger representation of women compared to other computing fields. In computing disciplines, at least four men earn an undergraduate degree for every woman, and this disparity increases for post-graduate studies [9]. Meanwhile, $80 \%$ of computer science publications are also authored by men [1]. However, the factors that shape gender imbalance in computing need to be better understood, even within SIGCHI. How might latent biases and more subtle acts of discrimination be brought to the fore? For instance, are there subcommunities within SIGCHI, who find themselves at a disadvantage because of the nature of research they engage in, for example, those who engage in feminist scholarship, such as ethics of care?

Imbalance of Institutional Representation Looking at the statistics for CHI 2017, a quarter of all publications last year came from only 19 institutions ( $3 \%$ of all institutions included in the $\mathrm{CHI} 2017$ proceedings) [5]. Of these 19 institutions, 10 were Ivy League or top-tier R1 universities within the United States. Is the high representation from these universities due to the quality of their research, or is it possible that a mixture of other factors, including intersectional biases, play a role? For instance, research shows that a single-blind review process (operative at the level of associate chairs within the SIGCHI review process) may introduce a number of biases and tend to favor researchers at higher-ranked universities, who already have more resources than their lower-ranked counterparts [15]. More research is warranted to 
understand the cause and implications of this unequal distribution on inclusivity within our community.

The ACM SIGCHI community has been growing exponentially and discussions around its sustainability are becoming quite frequent, often resulting in discussions on how to increase quality, but also threatening to narrow our field in ways which may unintentionally harm those who are already struggling to succeed. Exclusivity may also harm people who remain within our community because it denies them new and different perspectives from those who have been unintentionally excluded or remain at the margins; thus, less likely to be heard. How might we ensure that we do not create a community in which the rich get richer, the poor get poorer, and everyone loses the opportunity to learn from new perspectives and new domains? How might we distribute resources and costs across institutions and researchers, both in terms of time and money, in a way that is fair and equitable, and which opens worlds and viewpoints that were previously unknown to the community?

\section{Individual-Level Differences}

There are several other kinds of difference that exist at the individual level. For example, people might be differently-abled, and while there have been significant efforts within SIGCHI to support accessibility, we can move beyond adherence to published standards, to consider the actual experiences in conference settings, of researchers with disabilities. People might also have caregiving responsibilities, and while recent $\mathrm{CHI}$ conferences have made efforts to provide childcare, there remains little consideration of how these responsibilities are recognized and understood in terms of their impact on the researcher's time and financial resources. Further, people might be impacted by their cultural identities in less understood ways. For example, some might come from more collectivist cultures which affect authorship. Finally, personality may also make a difference; introversion/extraversion, for instance, effects how we engage with others. Advice to junior researchers often includes the suggestion that they should push themselves out of their comfort zones to ensure social engagement. Perhaps we might consider, instead, how SIGHCI events might be shaped to adapt to the characteristics of their attendees?

Our community is stronger and more knowledgeable through its diversity, with individual differences celebrated. As a community that prides itself on understanding and designing for individual differences, how may we apply these principles and values within our own field in a way that respects the intersectionality of our community?

\section{Panel Participants}

We selected our panelists to ensure representation across gender (two identify as male and three as female), nationality (North America, Europe, Australia, and Africa), and professional backgrounds (academia, industry, and practice). All have been proponents of equity and inclusivity within/beyond SIGCHI. As will be evident from the panel format specified below, we expect our panel to consist primarily of participation from the audience, with comments from the panelists in places that they see fit. Cliff, our moderator, will ensure that voices are heard equally and that they remain respectful across the room. Here we also draw on his extensive expertise within the SIGCHI community, where he wears many leadership hats all at once. Our panelists also include Susan, ACM Fellow as 


\section{WHY use I Like, I Wish, What If (ILIWWI)}

"Designers rely on personal communication and,

particularly, feedback, during design work. You request

feedback from users about your solution concepts, and you seek feedback from colleagues about design frameworks you are developing. Outside the project itself, fellow designers need to communicate how they are working together as a team. Feedback is best given with I-statements. For example, "I sometimes feel you don't listen to me" instead of "You don't listen to a word I say." Specifically, "I like, I wish, What if"

(IL/IW/WI) is a simple tool to encourage open feedback" [13]. of 2017, who has also been a recipient of the SIGCHI and UXPA Lifetime Achievement Awards, and was one of the founders of SIGCHI. We draw on her vast contributions towards making SIGCHI diverse in terms of both gender and ethnicity. Geraldine is a professor at TU Wien, with experience working in different countries, and in industry and academia. She is active in facilitating early career development workshops, as well as coaching/mentoring academics, and hosting the "Changing Academic Life" podcast series. She will also be the general co-chair for $\mathrm{CHI}$ 2019. Anicia has made foundational contributions to developing HCI capacity in Namibia in particular, but also Africa more generally. She chaired the first AfriCHI conference in 2016, and will be the $\mathrm{CHI} 2019$ Diversity and Inclusion chair. Themes of global inclusion and diversity are central to her efforts. Finally, Michael is at IBM Research AI and one of his research focuses has been the inclusion of diverse voices and constituencies in the design of technologies and work practices. He is Diversity cochair on the GROUP Conference Steering Committee.

\section{Panel: During and After}

Our 80-minute panel will be organized as follows:

- 0-10 mins: Brief introductions of panelists

- 11-20: Introduction of the ILIWWI format (see sidebar)

- 21-65: Moderated discussion that cycles between the audience and panelists, with each issue being presented by the audience in the ILIWWI format

- 66-75: Summary of takeaways from discussion and next steps to operationalize them

- 76-80: Wrap-up and thank-yous to all who participated with a provision of additional (moderated) channels to continue conversations
Creating a Safe Space

Our panel explicitly aims to break away from the traditional discourse we engage in as academics, which encourages debate around the validity and merit of certain ideas, to also serve as a safe space towards improving awareness on a diverse set of intersections that are present within the SIGCHI community. We plan careful moderation and facilitation to keep the discussions remain on topic and respectful. To ensure inclusivity and mutual respect, we plan to stress clear discussion guidelines (e.g., [14]) for fostering productive conversations within a safe space. We will also allow for anonymous inputs and feedback to be given with regards to the ongoing discussion, for which we will use an online anonymizing channel (e.g. Slido).

\section{Involving the Larger SIGCHI Community}

We will explore options for virtual participation, both online and through telepresence, during the panel, as well as recording the panel for later viewing. Once the panel concludes, we will also explore ways of continuing (moderated) discussions online for those interested.

\section{Panel Outcomes and Conclusion}

The primary objective of our panel is to facilitate conversations within the SIGCHI community on issues of equity and inclusivity by bringing awareness to a diverse set of intersections that could benefit the community through greater dialog. In this panel, we consider several "different kinds of difference." Some of these identities commonly intersect (e.g., women from Africa are more likely to be Black; researchers with caregiving responsibilities are more likely to be women) while others may be less common (e.g., caregiving men from emerging economies). Regardless of whether these intersections are more or less likely to occur, we 
emphasize the importance of acknowledging their existence and meaningfully working to include them, as a community that prides itself on understanding and designing for individual differences. We believe that our panel will provide the appropriate environment-given the experiences and backgrounds represented on our panel-to facilitate this important step. After the panel, will summarize the discussions that take place in the room as a blog post and, subsequently, write an Interactions article to engage the larger HCI community in this important on-going discussion.

\section{References}

[1] Bonham, K.S. and Stefan, M.I. 2017. Women are underrepresented in computational biology: An analysis of the scholarly literature in biology, computer science and computational biology. PLOS Computational Biology. 13, 10 (Oct. 2017).

[2] Brah, A. and Phoenix, A. 2013. Ain't I A Woman? Revisiting Intersectionality. Journal of International Women's Studies. 5, 3 (Jan. 2013), 75-86.

[3] Crenshaw, K. 1989. Demarginalizing the Intersection of Race and Sex: A Black Feminist Critique of Antidiscrimination Doctrine, Feminist Theory and Antiracist Politics. University of Chicago Legal Forum. 1989, (1989), 139.

[4] Fox, S. et al. 2017. Imagining Intersectional Futures: Feminist Approaches in CSCW. Companion of the 2017 ACM Conference on Computer Supported Cooperative Work and Social Computing (New York, NY, USA, 2017), 387-393.

[5] Institutions at CHI 2017: 2017. http://www.kashyaptodi.com/chi2017/institutions. Accessed: 2018-01-01.
[6] Kaye, J. et al. 2017. Policy Impacts on the HCI Research Community. Proceedings of the 2017 CHI Conference Extended Abstracts on Human Factors in Computing Systems (New York, NY, USA, 2017), 1300-1302.

[7] Kumar, N. and Dray, S. 2017. Crossing borders, building bridges. 34th. 24, (2017), 43.

[8] Muller, M. 2018. Revisiting an Ethnocritical Approach to HCI: Verbal Privilege and Translation. HCI remixed: Reflections on notable HCI papers. MIT Press.

[9] National Center for Education Statistics 2015. Digest of Education Statistics 2015.

[10] Nira Yuval-Davis 2006. Intersectionality and Feminist Politics. European Journal of Women's Studies. 13, 3 (Aug. 2006), 193-209.

[11] Schlesinger, A. et al. 2017. Intersectional HCI: Engaging Identity Through Gender, Race, and Class. Proceedings of the $2017 \mathrm{CHI}$ Conference on Human Factors in Computing Systems (New York, NY, USA, 2017), 5412-5427.

[12] Sobel, K. et al. 2017. Equity \& Inclusivity at IDC. Proceedings of the 2017 Conference on Interaction Design and Children (New York, NY, USA, 2017), 761-767.

[13] Stanford University d.school's method repository $I$ Like, I Wish, What If.

[14] The World Cafe 2017. A Quick Reference Guide for Hosting Word Cafe.

[15] Tomkins, A. et al. 2017. Reviewer bias in singleversus double-blind peer review. Proceedings of the National Academy of Sciences. 114, 48 (Nov. 2017), 12708-12713. 